International Journal of Solar Thermal

Vacuum Engineering

Journal homepage: https://akademiabaru.com/submit/index.php/stve/index ISSN: 2716-6953

\title{
Predictive permanent magnet synchronous generator based small-scale wind energy system at dynamic wind speed analysis for residential net-zero energy building
}

\author{
Asif Khan ${ }^{1}$, Saim Memon ${ }^{1 *}$, Zafar Said $^{2,3}$ \\ Solar Thermal Vacuum Engineering Research Group, London Centre for Energy Engineering, School of Engineering, London South Bank \\ University, London, United Kingdom \\ Department of Sustainable and Renewable Energy Engineering, University of Sharjah, P. O. Box 27272, Sharjah, United Arab Emirates \\ 3 U.S.-Pakistan Center for Advanced Studies in Energy (USPCAS-E), National University of Sciences and Technology (NUST), Islamabad, Pakistan
}

\begin{abstract}
Integration of small-scale wind energy system to residential buildings for a target to achieve net-zero $\mathrm{CO}_{2}$ emissions is a revolutionary step to reduce the dependency on the national grid. In this paper, a predictive 20 kVA permanent magnet synchronous generator (PMSG) based small scale wind turbine is investigated at dynamic wind speed with a sensing control system to manage and monitor the power flow for a supply to a typical residential building. A control system is applied that regulates the power from the wind turbine. Results indicate that the proposed control system maximizes the power efficiency within the system. The maximum power generation capacity of the wind turbine is $20 \mathrm{kWh}$ with $415 \mathrm{VAC}$ and $50 \mathrm{~Hz}$ frequency. A storage system of $19.2 \mathrm{kWh}$ that supplies the energy to the load side. The applied control unit improves the energy management and protects the power equipment during the faults. The research is conducted using MATLAB/SIMULINK and mathematical formulations.
\end{abstract}

Keywords:

Wind energy; PMSG; UPS; MPPT control

algorithm; MATLAB Simulation.

\section{Introduction}

Under all emission scenarios studied by IPCC in their published sixth assessment report 2021 [1], global surface temperature will continue to rise until at least the mid-century. Unless substantial reductions in carbon dioxide $\left(\mathrm{CO}_{2}\right)$ and other greenhouse gas emissions occur in the following decades, global warming of $1.5^{\circ} \mathrm{C}$ and $2{ }^{\circ} \mathrm{C}$ will be exceeded throughout the twenty-first century. In 2018, final energy accounted for $36 \%$, and $\mathrm{CO}_{2}$ emissions accounted for $39 \%$ in the worldwide building and construction sector [2-3]. The British Government revised the Climate Change Act in 2019 to commit the UK to reach net-zero emissions by 2050, up from an earlier aim of an $80 \%$ reduction in emissions by 2050 [3]. As a result, attaining net-zero energy building is critical and requires several progressive technologies such as vacuum glazing [6-12], triple vacuum glazing [1323], and translucent vacuum insulation panel [24-26] to minimize heat loss or cooling loss through the building fabric. For hot water, the use of solar thermal collectors [27], and nowadays the use of

\footnotetext{
* Corresponding author.

E-mail address: S.Memon@lsbu.ac.uk
}

https://doi.org/10.37934/stve.3.1.2949 
advanced vacuum based photovoltaic thermal collectors [28] with thermoelectric generator for harvesting waste heat energy into useful electrical energy [29-32], these provide hot water and electrical energy generation throughout a year at higher thermal and electrical efficiency. This is insufficient on its own. For this, a small-scale wind energy system can play a larger part in attaining net-zero energy building.

Small scale wind energy is suitable for the residential sector and offices as it will reduce dependency on the utility sources [33]. It is required to investigate the small-scale wind energy system to discover the best equipment and monitoring system to maximise the energy efficiency [34]. The energy storage system needs to be investigated for small-scale wind energy systems that improve the energy flow [35]. Parallel UPS based configuration is found suitable for this type of configuration. The parallel UPS based system transmits and stores the energy efficiently as compared to other UPS systems. The UPS can be integrated into photovoltaic modules but require environmental temperature control for optimal long-term operation of converters, such as water flow cooling [36] or microchannel heat sinks [37] as cost-effective measures for monocrystalline type PV modules [38,39].

The efficiency of a wind turbine depends on the design of turbine blades and striking wind speed. Due to changing wind speed, it is impossible to generate nominal power all the time because variable torque applies at changing wind speed. Smaller changes in the wind speed create a significant effect on the energy generation because power generation increases 8 times by a doubling wind speed [40]. Hence, it is imperative to correctly install the wind blades to extract maximum power from the wind energy system. Wind speed attacking angle and blades pitch angle is important to consider that impacts the power generation. The major parameters to improve the energy efficiency are pitch angle control, rated wind speed, and tip speed ratio. Wind turbine pitch angle adjustment also controls the rotor speed at high wind speed and captures more wind at lower wind times. By applying the correct pitch angle, a balance between turbine power and electrical power can be maintained [41]. The operating speed of the wind turbine is chosen between $3 \mathrm{~ms}$ to $15 \mathrm{~ms}$. Fig. 1 shows the direction of wind flow in the UK and the yearly average wind speed. Power efficiency increases by wind speed increment to a nominal level. When the wind speed is above the rated speed, then the wind turbine still generates the nominal power, but a braking system is required to reduce the overspeeding of the wind turbine rotary system.

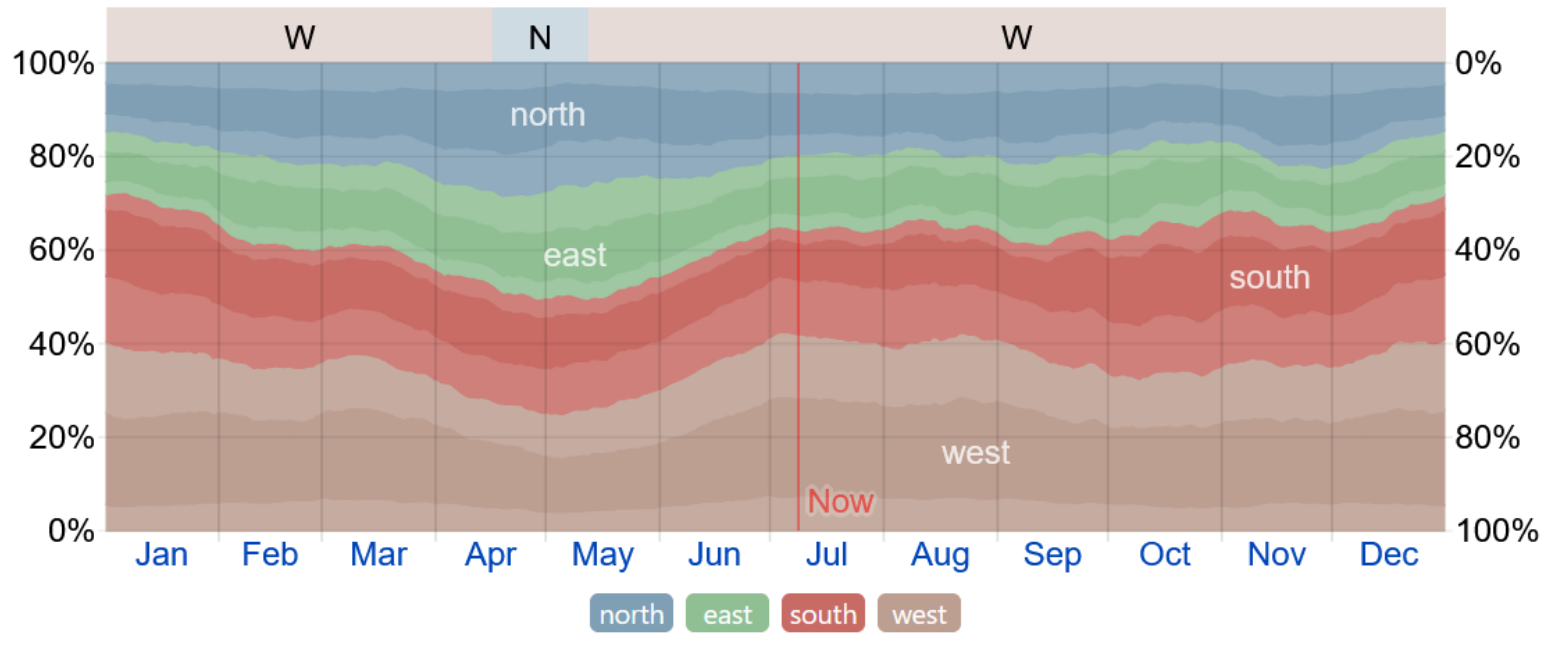

(a) 


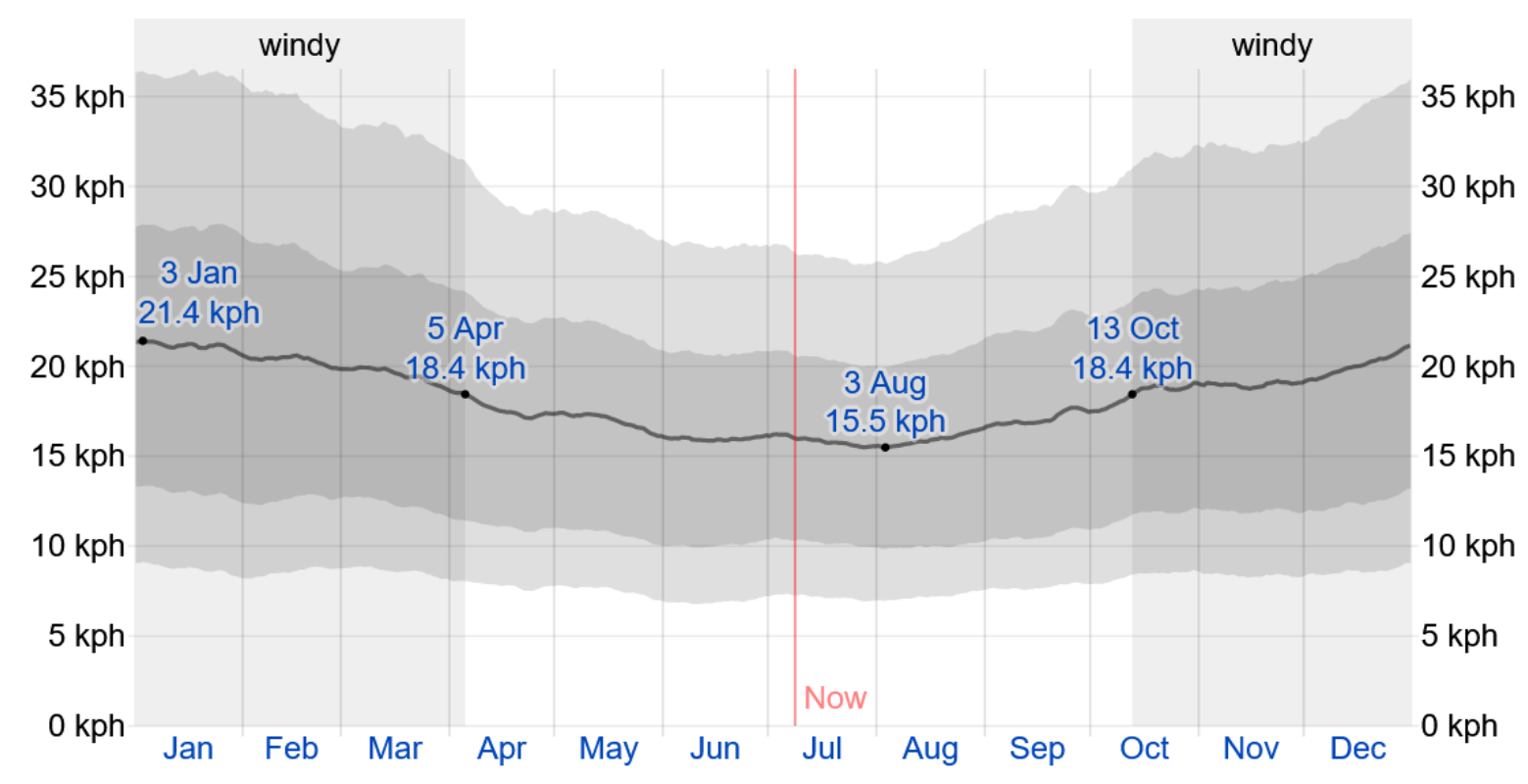

(b)

Fig. 1. (a) shows the yearly wind direction in the UK (b) yearly average wind speed in the UK [42].

In this research, a sensing system is designed to monitor voltage, current, and power to link with the control unit and power converters. The sensing systems also protect the components by isolating them at power fluctuations. The simulated maximum power point tracking (MPPT) algorithm-based control system regulates the power supply from a permanent magnet synchronous generator (PMSG) integrated into the wind energy system. This control system enables the power generation to be connected directly to the load and the storage system via rectifier/inverter. The system balances the power generation and the energy consumption to manage the power supply in the premises. It charges the storage system and supplies power to the load by using an inverter. The control system consists of stator side converters and inverters. Low pass filters are applied to remove the harmonics. The system consists of uncontrolled rectifiers, DC/DC buck-boost converters, and DC capacitor links. The voltage and current sensors are installed to maintain the power flow correctly. The inverter is used to converts the DC voltage to AC voltage connected directly to the load side. Pulse width modulation (PWM) strategies are set to maintain the switching frequency of IGBT based power converters. The Power flow is analysed by applying the variable wind speed. The power electronic converters are used to convert electrical power to connect it with the grid and storage system and voltage spikes. The simulation is completed on MATLAB/SIMULINK.

\section{Methodology}

\subsection{Wind turbine modelling}

The terminal output power from the wind turbine is given in Eq. (1) [43].

$P_{t}=\frac{1}{2} \rho \pi R^{2} C_{p}(\Lambda, \beta) v^{3}$

Where $\mathrm{R}$ is the wind turbine blade radius, $\mathrm{v}$ is the wind speed, $\rho$ is air density, $C_{p}$ is the turbine performance coefficient, $\beta$ is blade pitch angle, and $K$ is the tip speed ratio describe in Eq. (2).

$\Lambda=\frac{\omega_{m} R}{v}$ 
where $\mathbf{R}$ is the blade length and $\omega_{m}$ wind turbine rotor speed. The turbine output mechanical torque is described $T_{m}$ as [44].

$T_{m}=\frac{1}{2} \rho A C_{p}(\Lambda, \beta) v^{3} \frac{1}{\omega_{m}}$

The power coefficient of the wind turbine is given in Eq. (4).

$C_{p}=\frac{1}{2}\left(\frac{116}{K_{i}}-0.4 \beta-5\right) e^{-\left(\frac{21}{K_{i}}\right)}$

$\frac{1}{\Lambda_{i}}=\frac{1}{\Lambda+0.08 \beta}-\frac{0.035}{\beta^{3}+1}$

The parameters of nominal power parameters for the wind energy model are shown in the Table. 1.

Table 1

Parameters of the wind energy based system

\begin{tabular}{ll}
\hline PMSG & $415 / 50 \mathrm{HZ}$ \\
PMSG Nominal Power & $20 \mathrm{kVA}$ \\
Storage system & $20 \mathrm{kWh}$ \\
Converters & $\mathrm{AC} / \mathrm{DC} / \mathrm{AC}$ \\
Wind speed & $3 \mathrm{~m} / \mathrm{s}-15 \mathrm{~m} / \mathrm{s}$ \\
Maximum applied load & $9.2 \mathrm{kWh}$ \\
Utility & $230 \mathrm{VAC} / 50 \mathrm{HZ}$ \\
UPS Configuration & Parallel system \\
Control system & P\&O (MPPT)
\end{tabular}

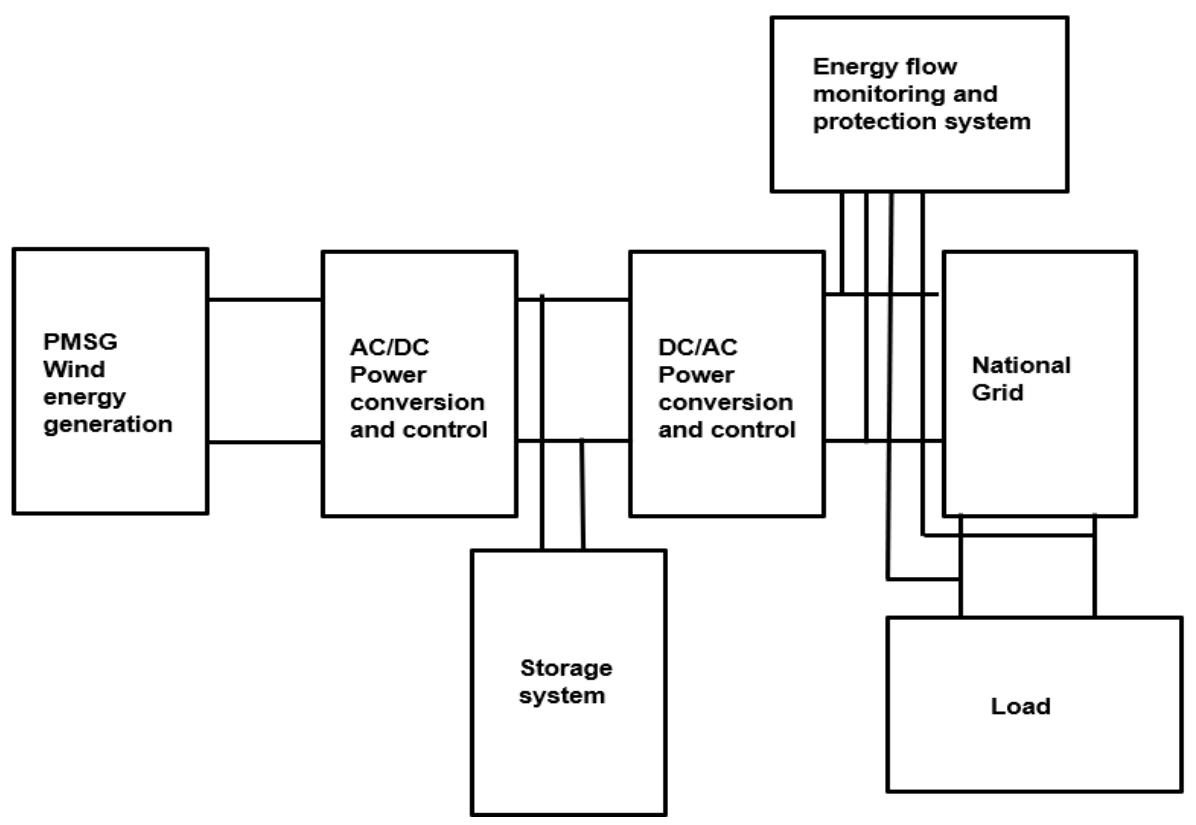

Fig. 2. Schematic diagram of the proposed model. 
Variations in tip speed ratio occur by changes in wind speed or generator speed that affect the power generation. The maximum power can be extracted using appropriate control systems such as the maximum power point tracking algorithm (MPPT) $[45,46]$. In this research, different wind speed values were chosen to observe and suitably control the output power. The wind speed values fluctuate with time, repeating every second. The voltage level is not constant with the varying wind speed where the control system is applied to fix the output voltage from the wind turbine. The schematic diagram of the proposed model is shown in Fig. 2.

\subsection{Modelling of Permanent Magnet Synchronous Generator (PMSG)}

PMSG is feasible for low scale wind energy systems because it provides constant output frequency at variable wind speed and has better energy efficiency. It has higher reliability with less weight and operates efficiently at a variable wind speed. It consists of permanent magnet on the rotor instead of windings that reduces generator complexity and improves generator life scale [47]. A gearbox can be incorporated in the PMSG based wind turbine to maintain the revolution per minute of the generator speed. Mainly gearbox is used to achieve the required high rotor revolution. This generator also operates without the needing for a gearbox. PMSG is excited by permanent magnets that stop the exchange of power between generators and converters. The revolution per minute in PMSG can be maintained by increasing the number of poles. The simulation of permanent magnetbased wind energy system is shown in Fig. 3.

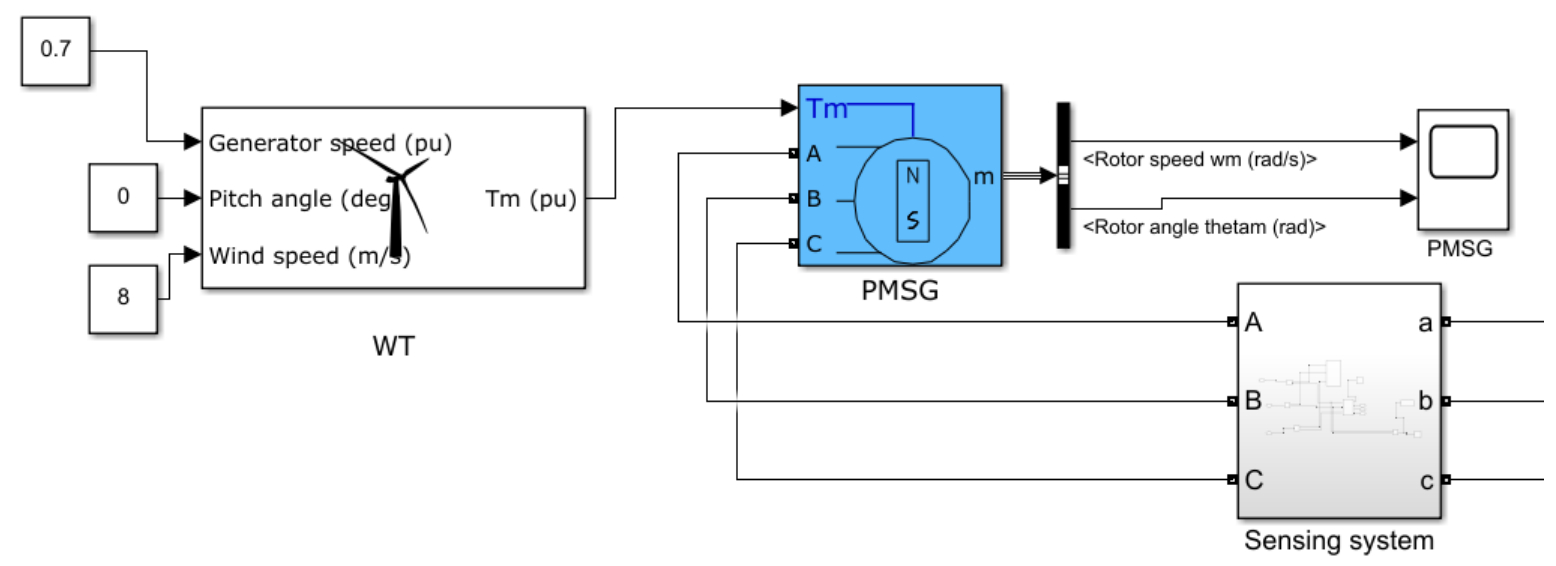

Fig. 2. Modelling of permanent magnet synchronous generator-based wind unit.

The modelling of the permanent magnet synchronous generator is defined as [48].

$$
\begin{aligned}
& V_{g q}=\left(R_{g}+p \cdot L_{q}\right) i_{q}+\omega_{e} L_{d} i_{d}+\omega_{e} \\
& V_{g d}=\left(R_{g}+p \cdot L_{d}\right) i_{d}+\omega_{e} L_{q} i_{q}
\end{aligned}
$$

$V_{g q}$ and $V_{g d}$ are direct stator and quadrature stator voltage. $i_{q}$ and $i_{d}$ are the quadrature stator current and direct stator current, $R_{g}$ represent the stator resistance and $L_{d}$ and $L_{q}$ are the inductance, $\omega_{e}$ is the rotational speed of the rotor and $W_{f}$ is the magnetic flux. The rotating speed of the generator is given by Eq. (8).

$\omega_{e}=p_{n} w_{m}$ 
$\omega_{m}$ is the angular speed of he generator and $p_{n}$ defines the number of poles pair of the generator.

The electromagnetic torque of the PMSG is described as.

$T_{e}=\frac{3}{2} p_{n}\left[i_{q}-\left(L_{d}-L_{q}\right) i_{d} i_{q}\right]$

If $i_{d}=0$ then the electromagnetic torque is given by

$T_{e}=\frac{3}{2} p_{n} i_{f} i_{q}$

The dynamic term for the wind turbine is as follows.

$j \frac{d \omega_{m}}{d t}=T_{e}-T_{m}-F \omega_{m}$

$F$ is the coefficient of viscous friction, $J$ is the moment of inertia and $T_{m}$ is the developed mechnical torque from the wind turbine.

Table 2

Specifications of permanent magnet synchronous generator (PMSG).

\begin{tabular}{ll}
\hline Voltage & $415 \mathrm{~V} / 5 \mathrm{OHZ}$ \\
Nominal Power & $20 \mathrm{kVA}$ \\
Rotor type & Round \\
Wind speed & $3 \mathrm{~m} / \mathrm{s}-15 \mathrm{~m} / \mathrm{s}$ \\
Stator phase resistance & $2.875 \Omega$ \\
Armature inductance & $0.000835 \Omega$ \\
Output voltage & Variable \\
Mechanical input & Torque Tm \\
\hline
\end{tabular}

\section{Results and discussion}

\subsection{Simulated PMSG at dynamic wind speed analysis}

Fig. 4 shows the energy generation at variable wind speed. At $3 \mathrm{~m} / \mathrm{s}$, the output voltage is lower, but voltage increments is noticed with the wind speed.

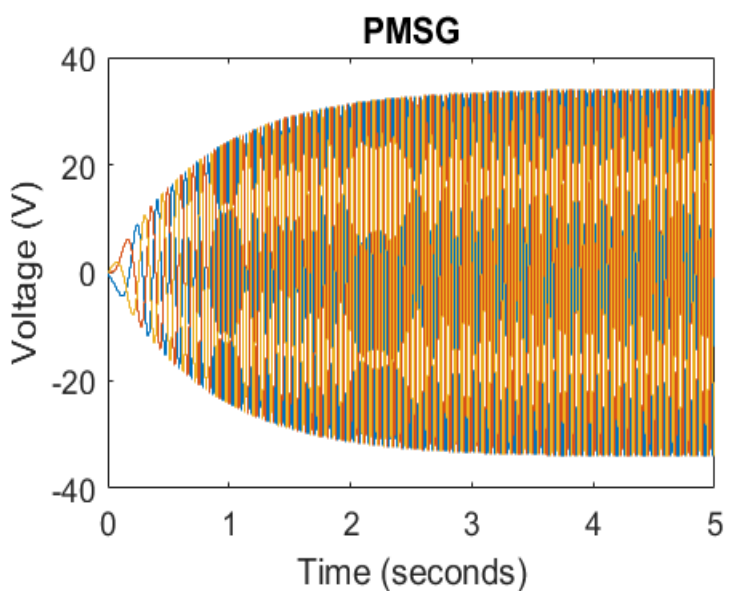

(a)

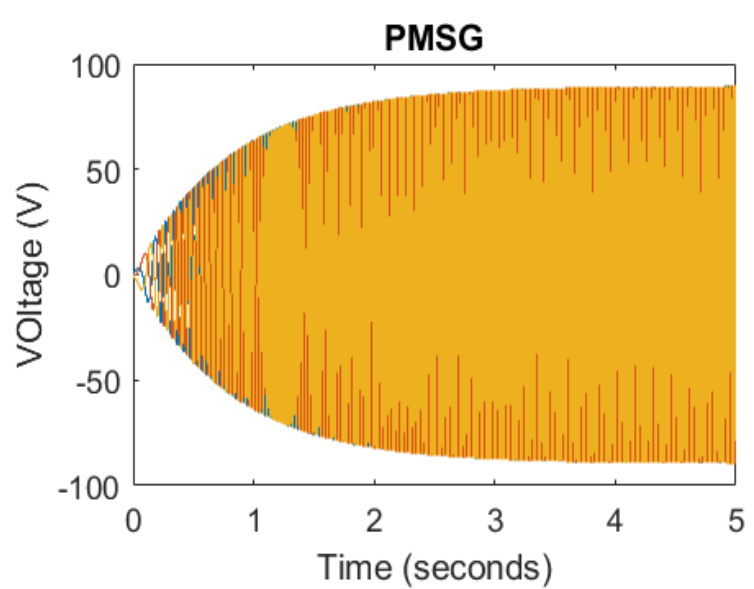

(b) 


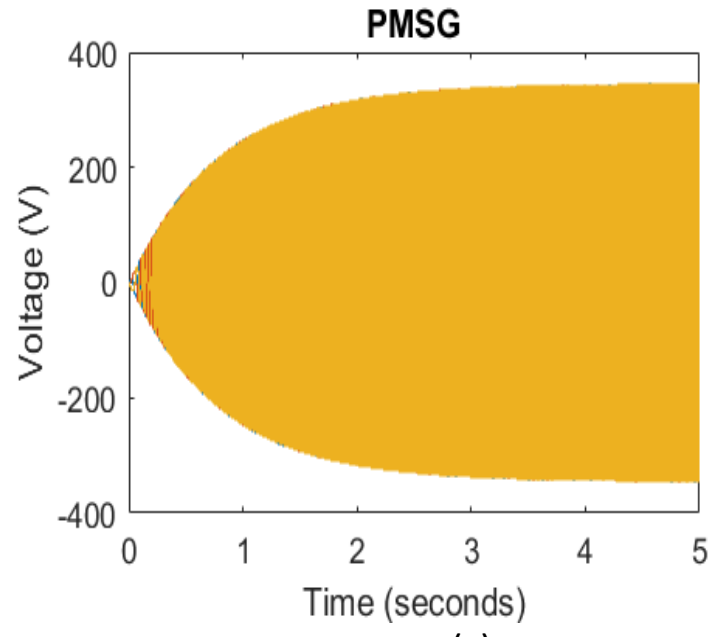

(c)

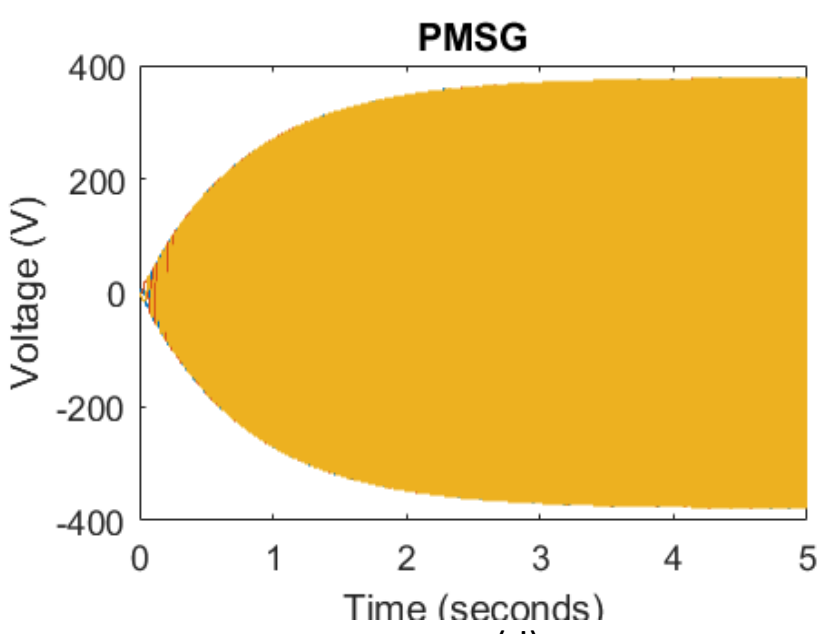

(d)

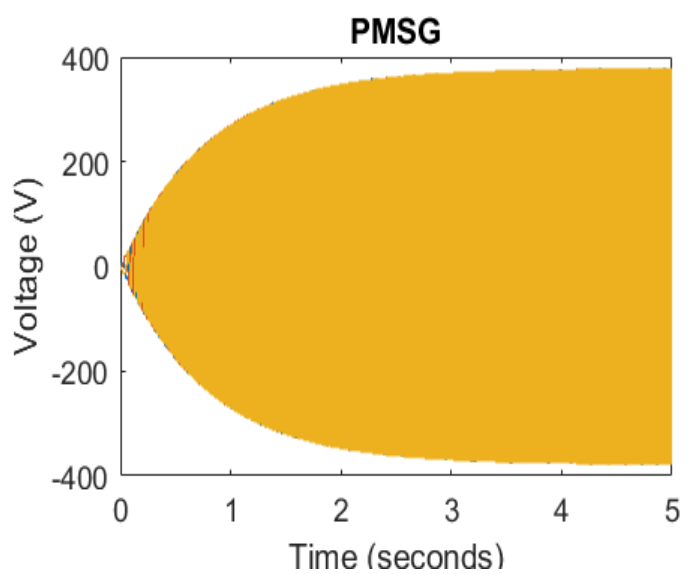

(e)

Fig. 4. (a) Voltage at $3 \mathrm{~m} / \mathrm{s}$ wind speed. (b) voltage at $6 \mathrm{~m} / \mathrm{s}$ wind speed. (c) Voltage at $9 \mathrm{~m} / \mathrm{s}$ wind speed (d) Voltage at $12 \mathrm{~m} / \mathrm{s}$ wind speed. (e) Voltage at $15 \mathrm{~m} / \mathrm{s}$ wind speed.

\subsection{Simulation of control unit on the stator side converters}

The power flow from the PMSG fluctuates AC type, and it needs to be regulated before connecting it to the load side and the storage system. It is converted to DC type to achieve the regulation by using six insulated gate bipolar transistors (IGBT) $[49,50]$. The two diodes are connected in every three rows to achieve the voltage conversion to DC type. The upper diodes are connected to the live terminal, and the lower diodes are connected to the neutral terminal of the PMSG output. These six diodes convert the power from the wind turbine unit to DC type in a controlled way. Fig. 5 demonstrates the voltage rectification from the variable wind speed. This voltage is then regulated to 6OVDC to charge up the storage system. 


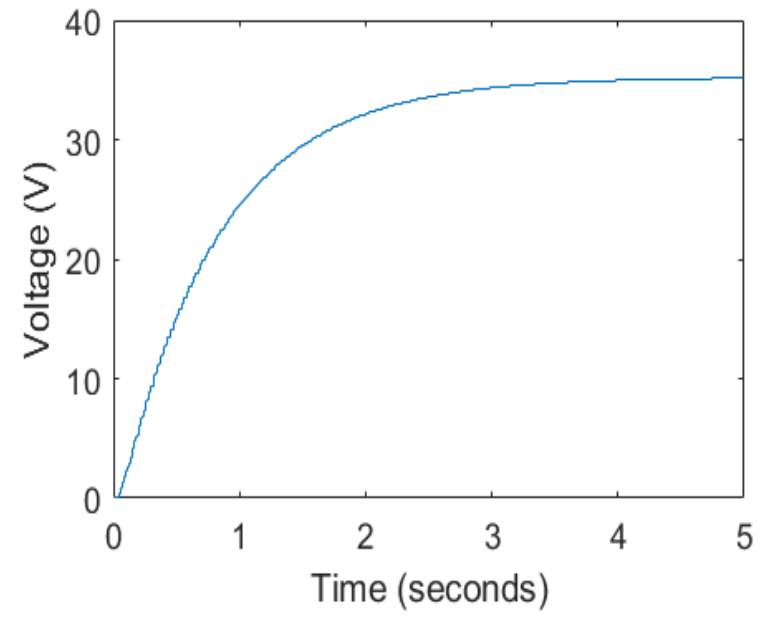

(a)

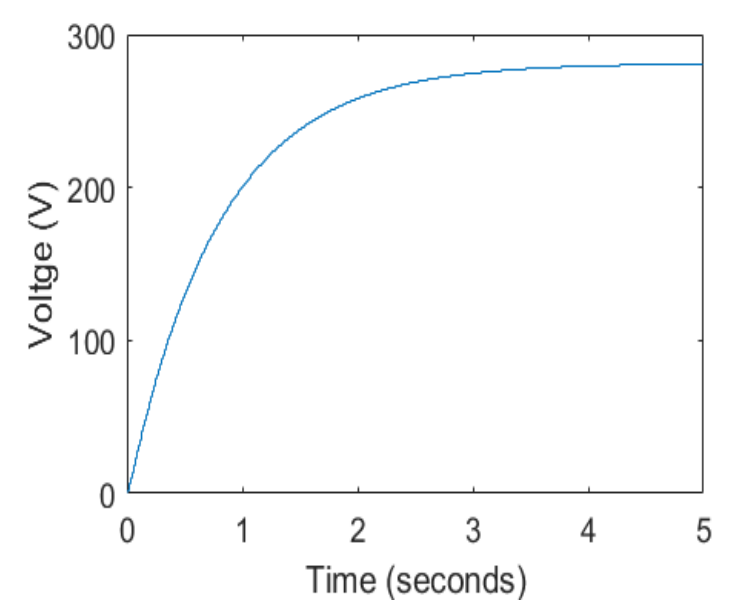

(c)

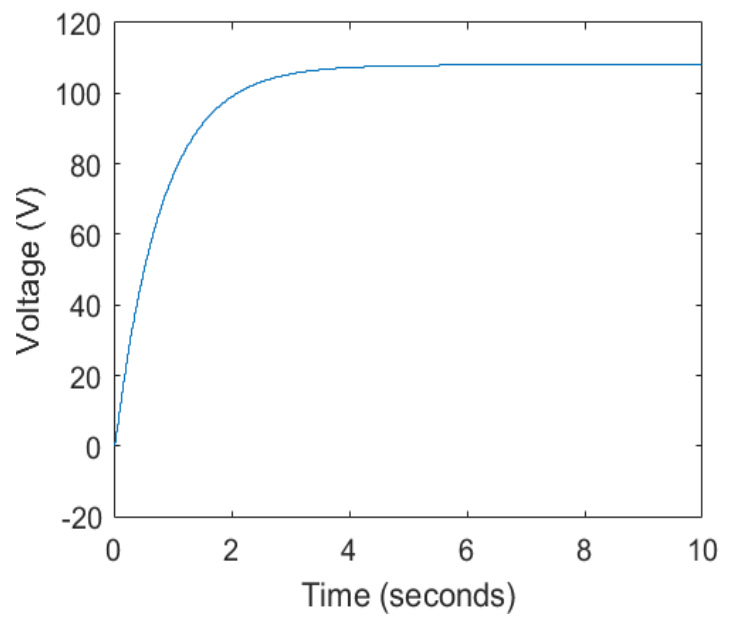

(b)

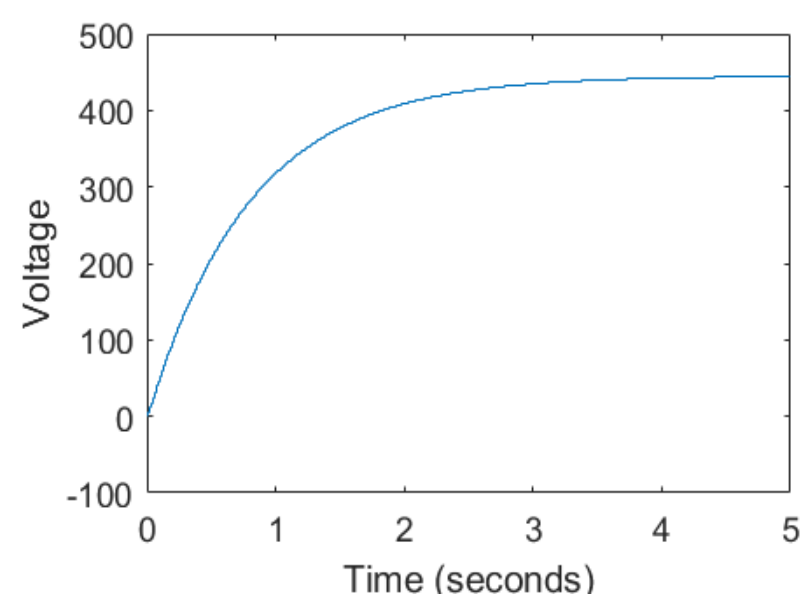

(d)

Fig. 5. AC/DC voltage conversion at variable wind speed in an uncontrolled $A C / D C$ rectification.

Buck-Boost converter is applied to maintain the variable voltage from the PMSG uncontrolled rectifiers. These converters maintain the voltage according to the reference voltage. The basic components used in the converters are insulated gate bipolar transistors, chopper circuits, capacitors, and inductive elements. The frequency of the IGBT switches is low, so a new controlled frequency is applied to control the speed of the switches. The desired voltage is achieved by adjusting the duty cycle from the control system. The voltage is boosted by increasing the duty cycle. Capacitors are used to remove the oscillations from the system. Perturb, and observation techniques are applied to control the voltage on the stator side of PMSG based wind energy system. 


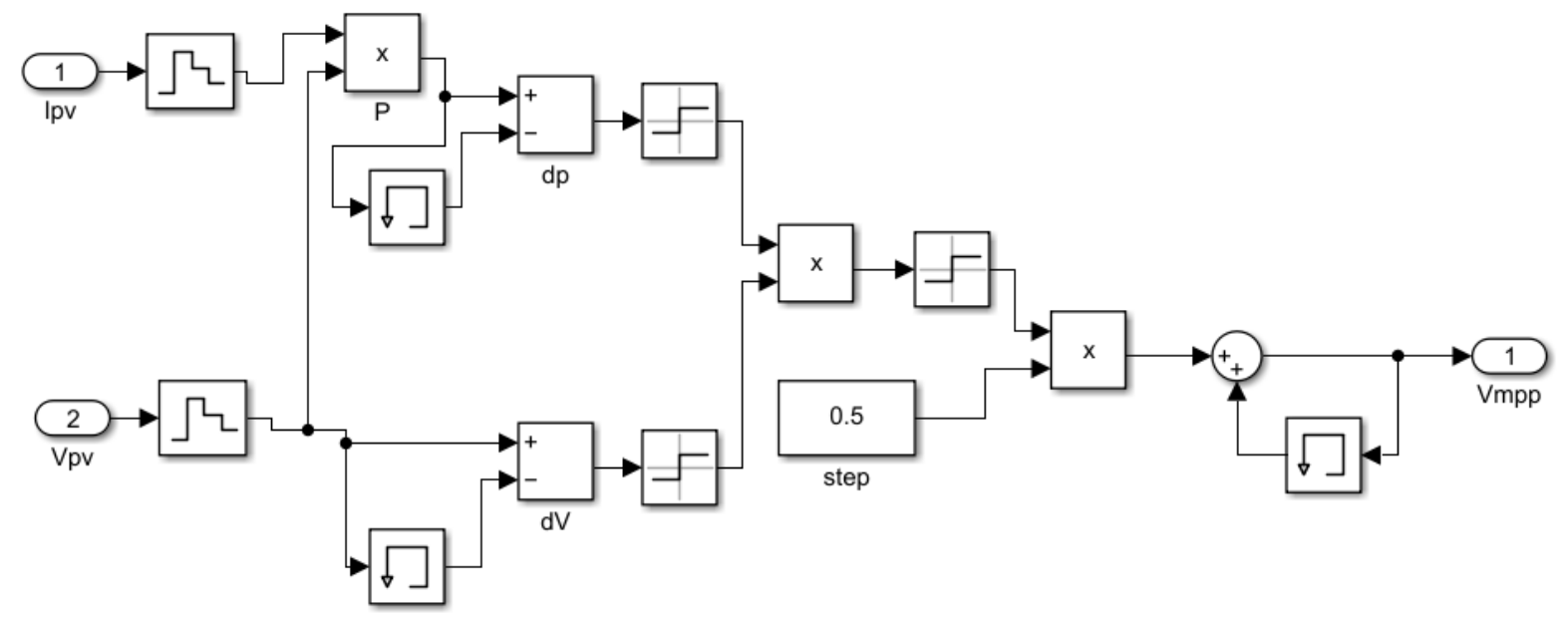

Fig. 6. Shows the perturb and observes algorithm used to investigate the regulation in wind energy.

This system senses the voltage and power by using sensors. It maintains the output voltage from PMSG at a variable wind speed. The regulated voltage to charge up the storage system is shown in Fig. 7. It also boosts the voltage to achieve the reference voltage. This method is suitable for changing windy conditions, specifically for PMSG [51]. The oscillations are observed by using $\mathrm{P}$ and $\mathrm{O}$ and are removed by using filters. This method is better economically, achieves better efficiency, and can be applied with reduced hardware equipment. A DC chopper circuit is also installed in the DC link stator side conversion system. This chopper circuit will protect the DC link circuit in the case of imbalances in the system. When the imbalances happen, the system observes a voltage reduction on the grid terminals [52,53], which reduces the power flow in the system and increases the load on the stator side converters. The chopper circuit will dissipate the excess power by the applied resistance systems.

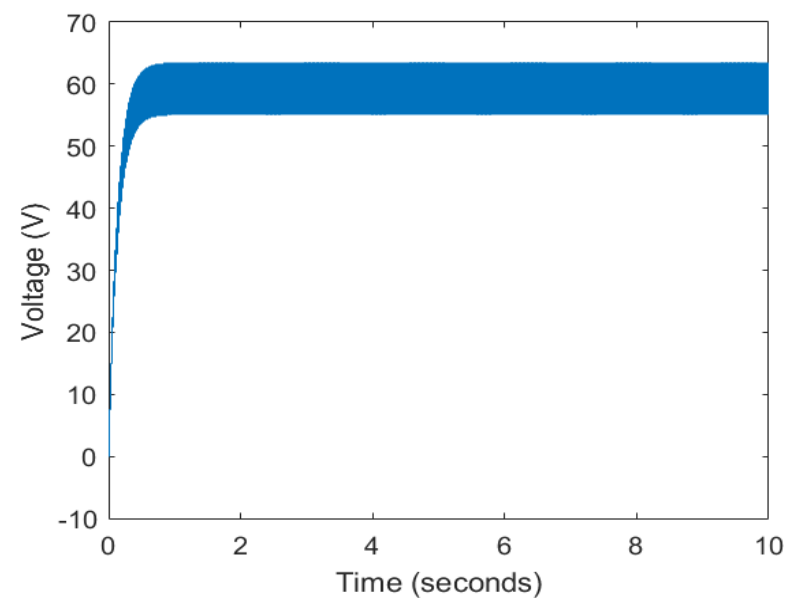

(a)

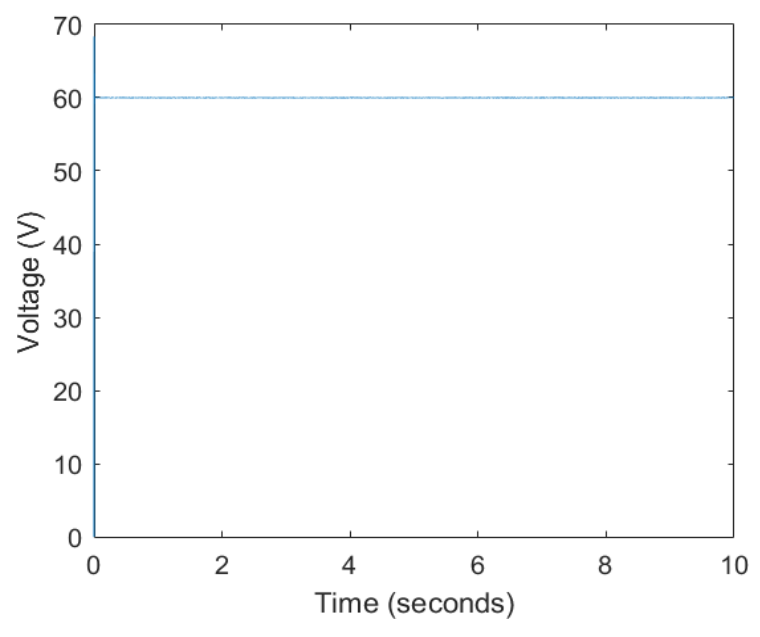

(b)

Fig. 7. (a).16VDC voltage to charge up the storage systems, (b) 16VDC voltage without oscillations.

\subsection{Simulation of Sensing System to the power flow}

Simulation is performed on MATLAB/SIMULINK to investigate the improvement in power flow from small scale wind turbine units. The proposed system improved the power flow efficiency and reduces losses by drawing maximum power from wind units. It supplies regulated voltage irrespective of variations in the wind speed. The system can deliver power to the load all the time. The control 
system senses the unregulated voltage from the wind turbine and generates the correct duty cycle to maintain the voltage, as shown in Fig. 8.

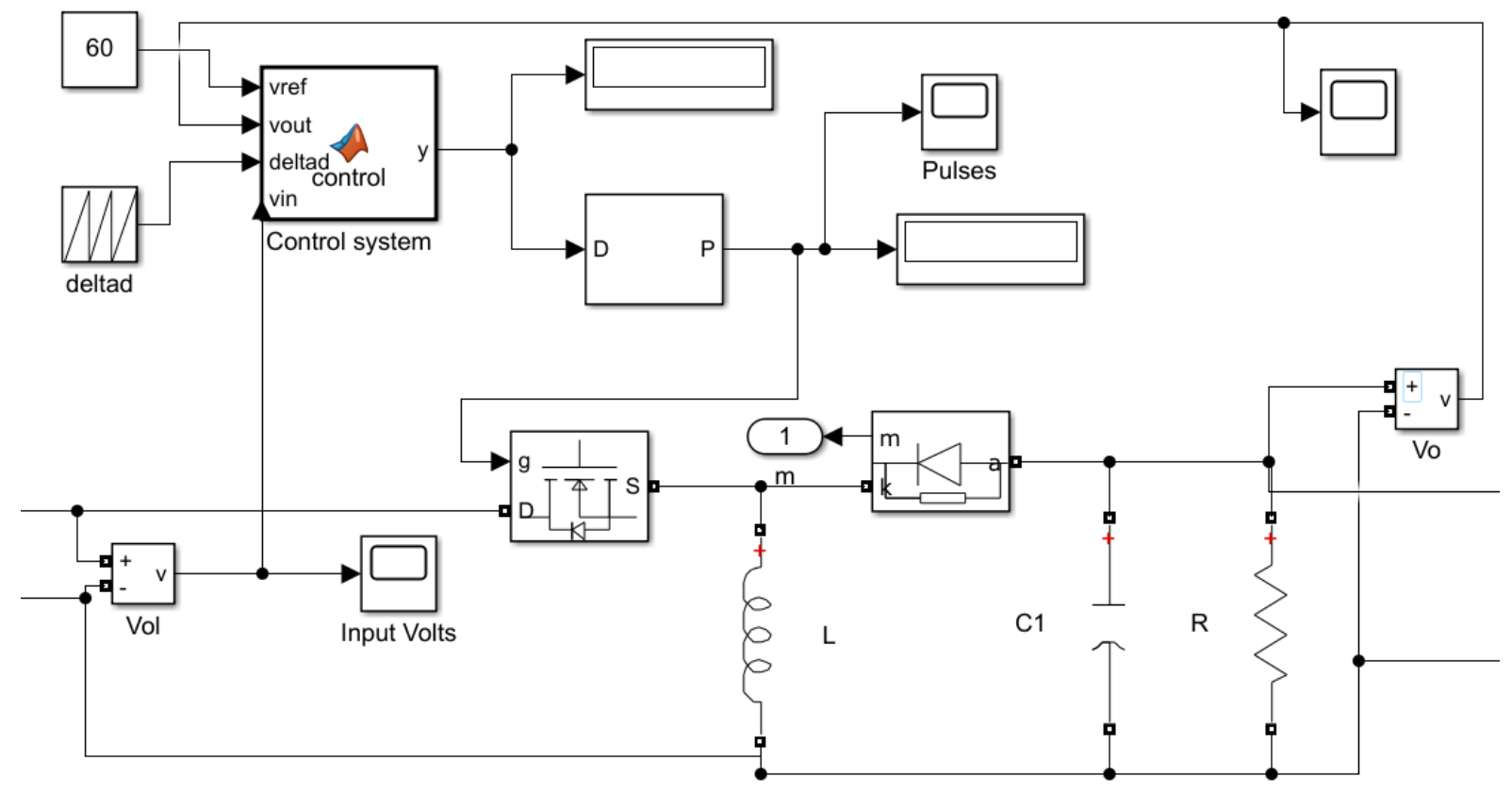

Fig. 8. Buck-Boost converter to regulate DC/DC voltage.

Oscillations are noticed in the power flow that is reduced by applying low pass filters. Inductance and switching frequency affect the power flow in the system. Higher inductance and higher switching frequency of the insulated gate bipolar transistor reduces the ripples in current and vice versa. The losses in the system are negligible due to the shorter transmission system. The inverter supplies 230 VAC power to the load. The inverter receives power from the storage system and directly from the wind turbine system at rated wind speed. The sensing system is applied at every point of the system to measure and maintain the power flow, as shown in Fig. 9. A circuit breaker is installed to protect the power components at every section of the system. The applied maximum power point tracking algorithm stabilised the power flow and maintained the voltage to charge up the batteries. 


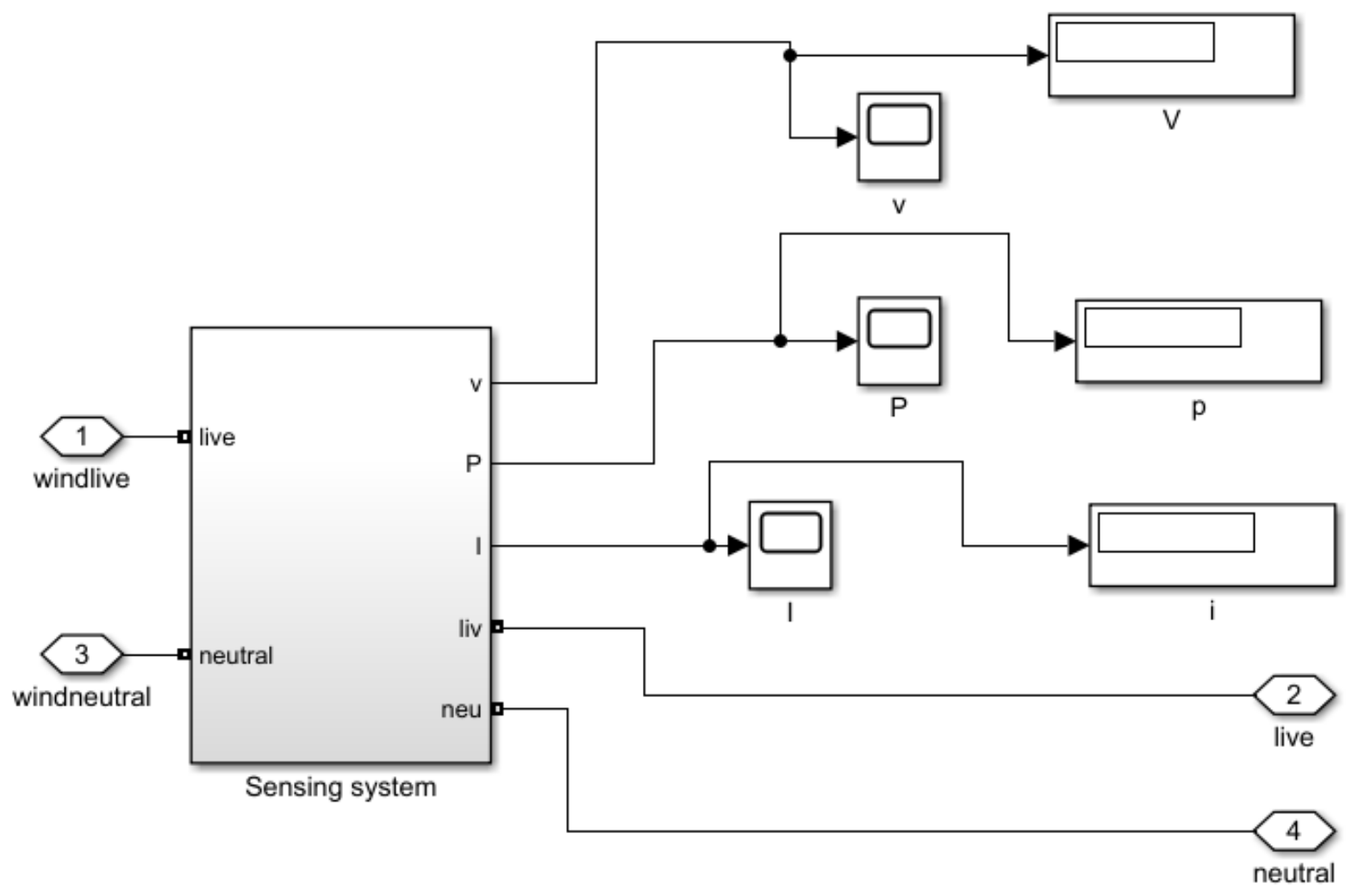

Fig. 9. Sensing systems to monitor the power flow across different points of the design model.

The DC/AC inverter aims to transfer the regulated $A C$ power to the load, as shown in Fig. 10. It converts DC/AC voltage in a stabilised way. There are four IGBT switches used to convert DC voltage into AC voltage. The PWM waveform is applied to achieve the correct voltage and frequency. The stabilised $230 \mathrm{VAC}$ is then directly connected to the residential sector. The technique used to convert DC voltage into AC voltage is SPWM, where the duty cycle is applied between 0 and 1 by switching $\mathrm{ON}$ and OFF to generate AC voltage, as shown in Fig. 11.

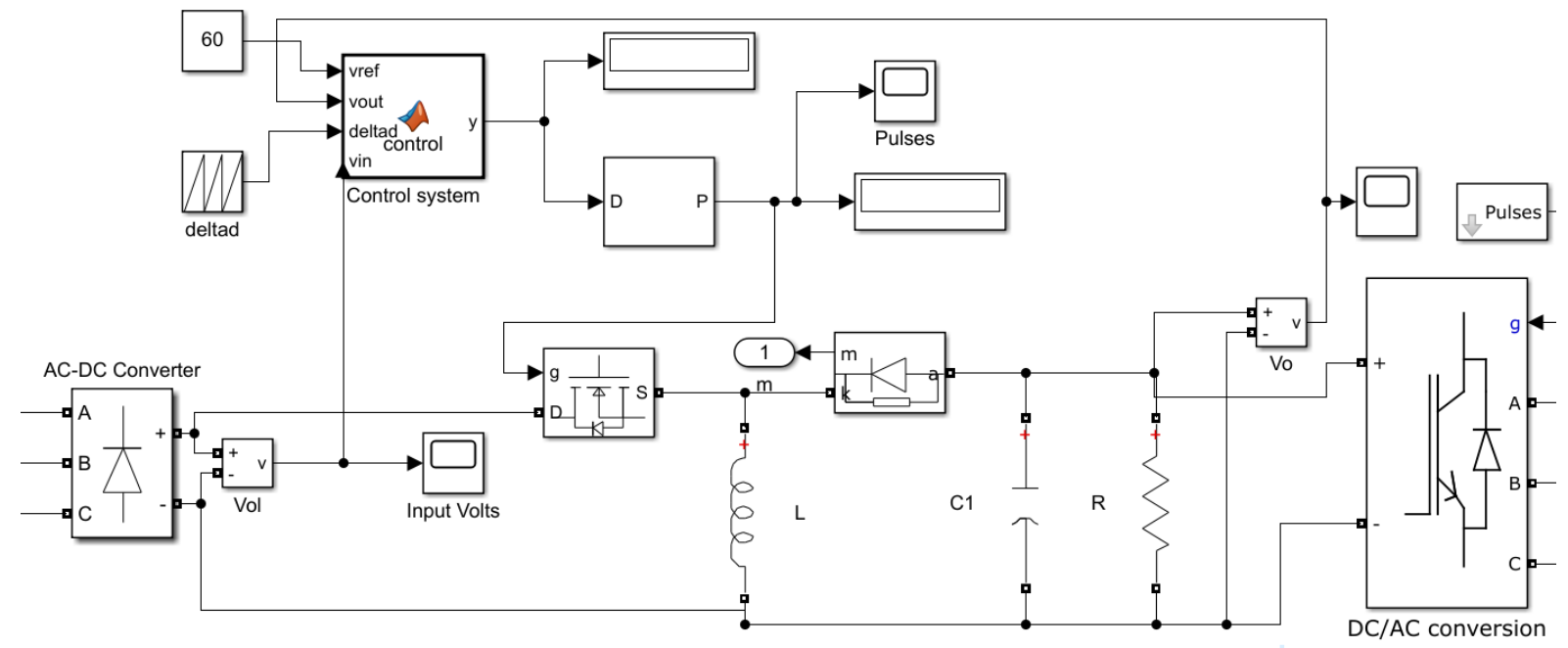

Fig. 10. illustrate the complete circuit of $A C / D C / A C$ power conversion. 


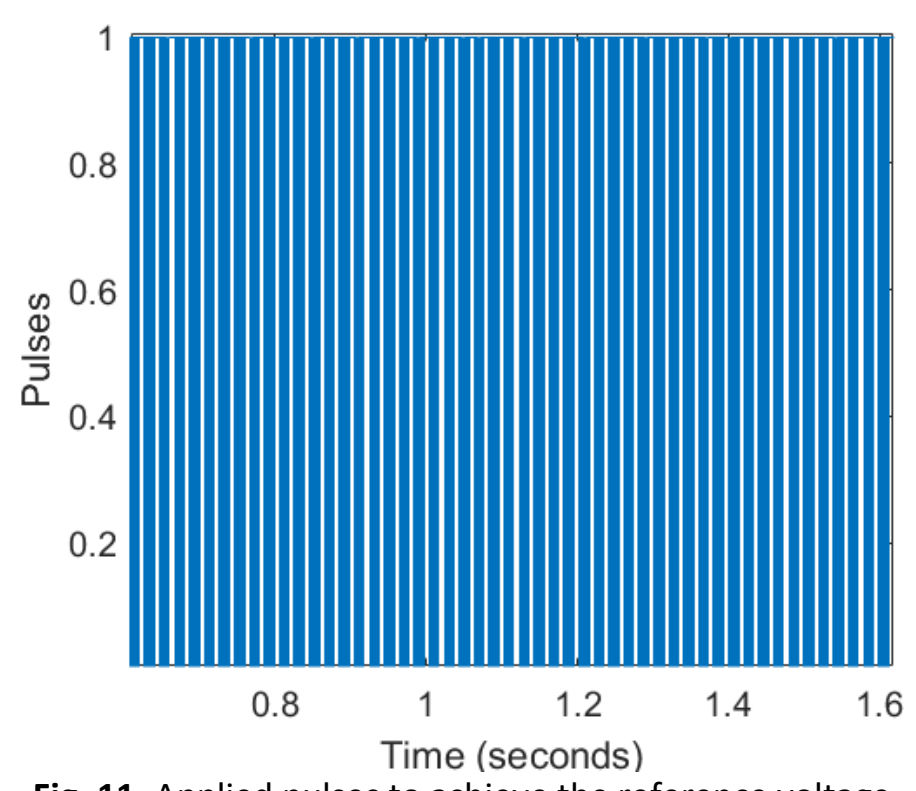

Fig. 11. Applied pulses to achieve the reference voltage.

The generated harmonics in the output are removed by using a filter. The power quality of the wind energy generation system depends on whether the output voltage and frequency are close to the nominal values because PMSG is a variable power generation system, so it is required to balance the output power variables [54]. The output voltage and frequency should be kept constant before connecting it to the load side or the grid in the changing environmental conditions. The controller applies the correct pulses to achieve the desired output at the load side. The output signal from the applied control system is shown in Fig.12. There are sensors installed to monitor the power flow to the load side.

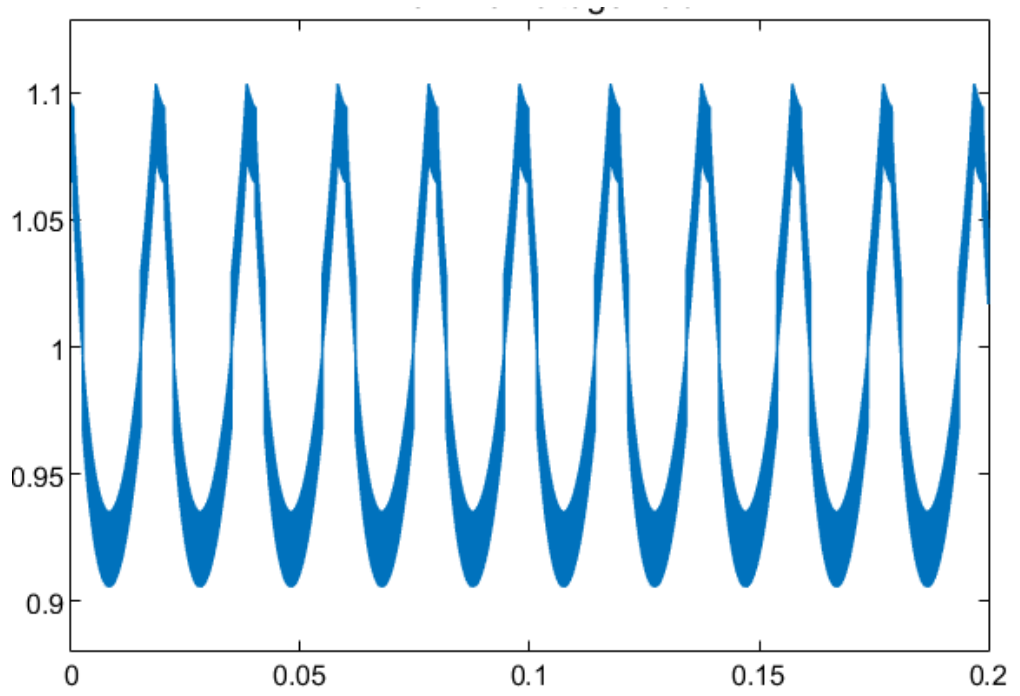

Fig. 12. Output signal from the controller to apply correct pulses

The protection system shown in Fig. 13 is used to protect the load and the grid synchronisation when fluctuating voltage from the inverter. Harmonics components are noticed because of PWM switching elements. These harmonics components reduce the working efficiency of the loads so a filter is placed between the load and the converter to minimise the effect of these harmonics. 


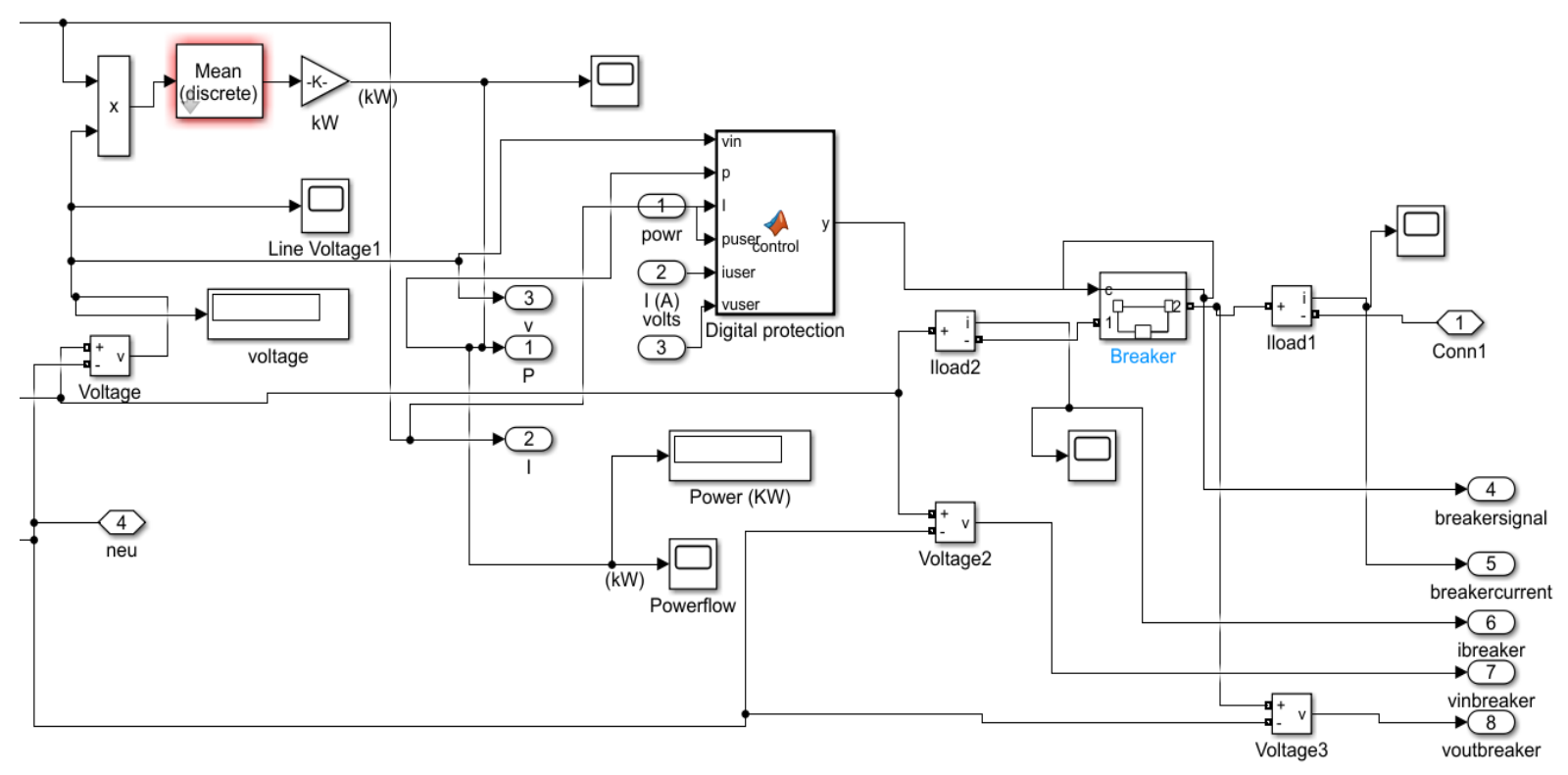

Fig. 13. illustrates the protection systems used to protect the power components during the fluctuations in voltage or short circuits.

\subsection{Importance of UPS systems}

Selection of a correct UPS configuration is essential for this type of energy flow system. Different types of UPS configurations are investigated to choose the suitable configuration. The factors that are considered during the design of UPS systems are reliability, fault clearance times, human errors, and maintenance timings. It is also considered that all UPS system has to be maintained regularly; therefore, it is crucial to design a system with high reliability [55]. After investigating different types of UPS modules, it is found that parallel UPS modules are more efficient because failure of one component in this type of system will not cause failure of the entire system and can still supply energy to the load. This type of design makes it possible to drive the loads under fluctuated wind energy generation systems. If the available power from the wind system is low, then loads can be transferred to the main grid.

Table 3

The battery storage specifications.

\begin{tabular}{ll}
\hline Rated Voltage & $48 \mathrm{~V}$ \\
Current Capacity (A) & $200 \mathrm{Ah}$ \\
Nominal Power & $9.6 \mathrm{kWh}$ \\
Converters & AC/DC/AC \\
Float charge & $54 \mathrm{VDC}$ \\
Absorption charge & $58.8 \mathrm{VDC}$ \\
\hline
\end{tabular}

This system will allow to eliminate the single point of failure in the system and increase reliability, and it operates as a standalone system to meet most of the energy demands for the residential sectors and offices. Two separate power paths in this design will ensure continuity of power supply to the loads, as shown in Fig. 14. 


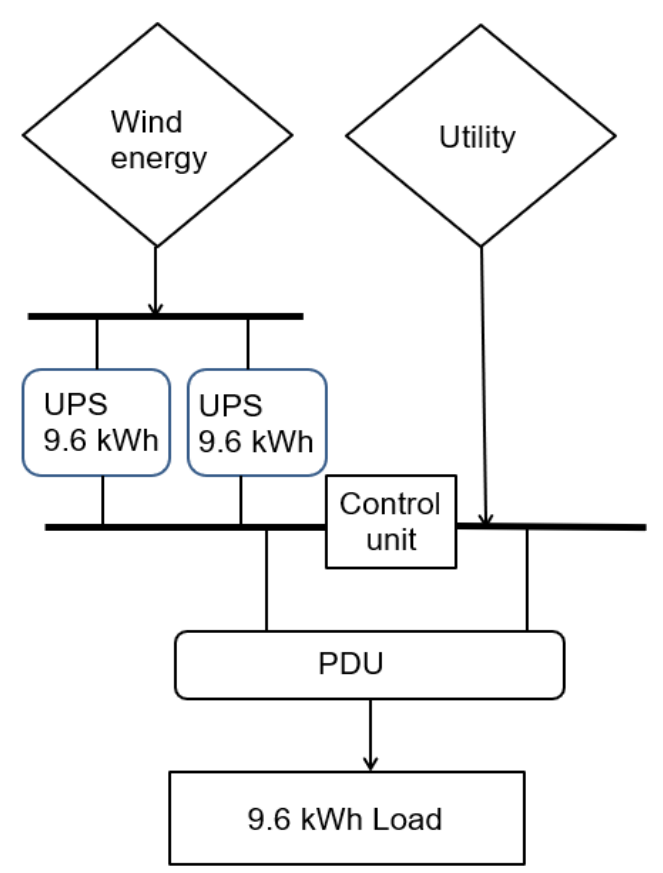

Fig. 14. The model of the parallel UPS design.

Parallel UPS configuration allows the system to continuously supply power to the load from the variations and outages in the wind speed. If the loads capacity grows, then more UPS can be installed in parallel to meet the energy demand. The charging features of the battery storage system is shown in Fig. 15.

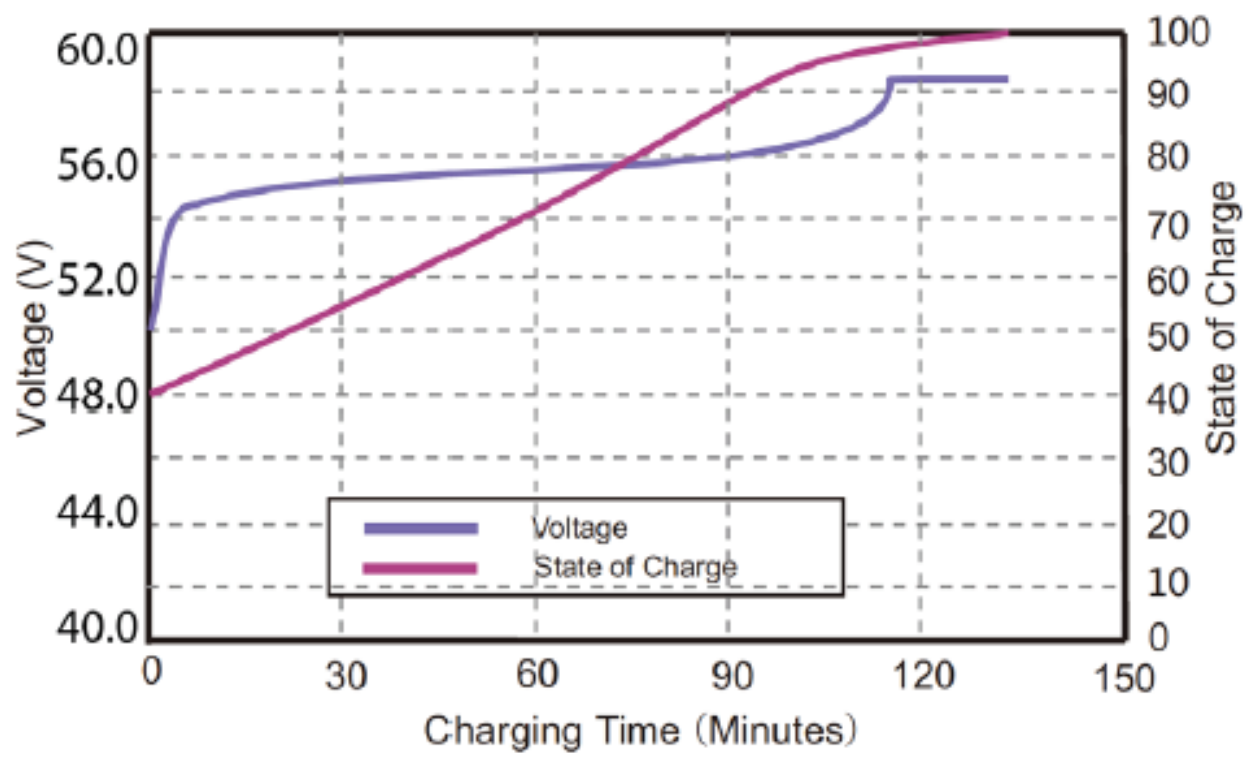

Fig. 15. Shows the state of charge curve. [56]

During the normal operations, both UPS supplies energy evenly to the load. When one of the modules is failed, then the remaining system should supply energy to the load. The efficiency of the parallel UPS system is much better because all modules are operational all the time, and fewer circuit breakers are installed. This reduces the cost and complexity of the entire wind energy system [57]. It is also possible to install multiple units in the same configurations. The rectifier receives the DC power from wind energy and charges up the battery. The inverter receives the power from the rectifier and 
converts it into AC power to supply the load [58]. During normal conditions, it directly receives power from the rectifier and from the battery when there is no power coming from the rectifier.

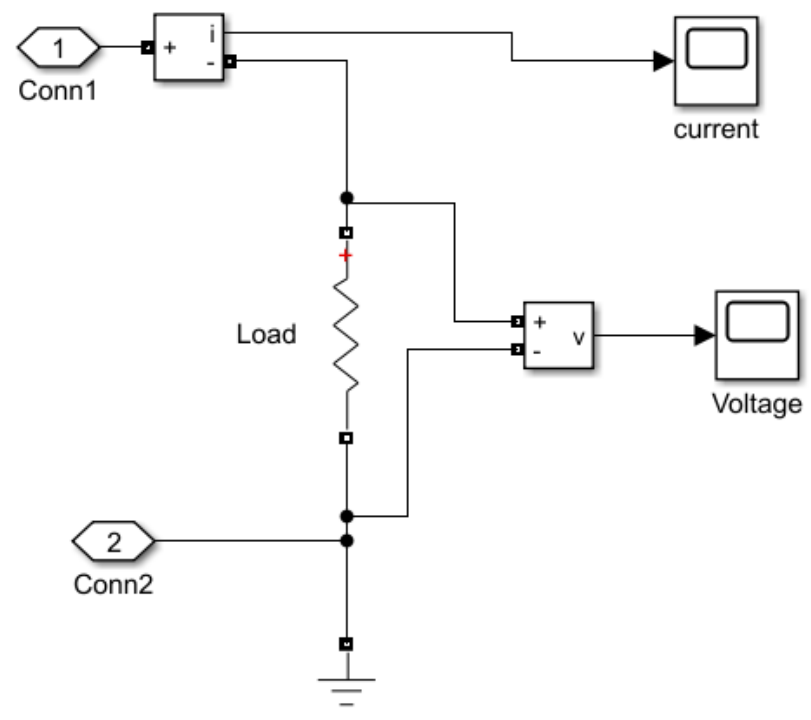

Fig. 16. Illustrates the power load receiving power from the UPS/utility

\subsection{Understanding the risk and reliability analysis of wind energy storage systems}

Risk analysis is carried out to discover the consequences caused by changing environmental conditions. Suitable methods such as the bath curve shown in Fig. 17 ensure the continuity of energy supplies to the load [59]. Risk is viewed as the failure of any components and how these components can reduce the energy supplies and possible consequences during this time. There is an alternative measure taken to improve the energy efficiency if the risk level is not acceptable. Reliability of applied uninterruptible power (UPS) is paramount where many UPS designs are focused, and a parallel redundant system is chosen to meet the energy demands [60]. The wind energy is to be stored in the parallel UPS modules. If one of the modules goes faulty or needs maintenance, the other UPS module will supply power to the load. If there is no power available from the UPS, the utility will fully energize the load. Regular testing and the use of high-quality components will improve the quality and reliability of the entire system. A bath curve is used to visualise the reliability of the wind energy system and UPS module [61]. 


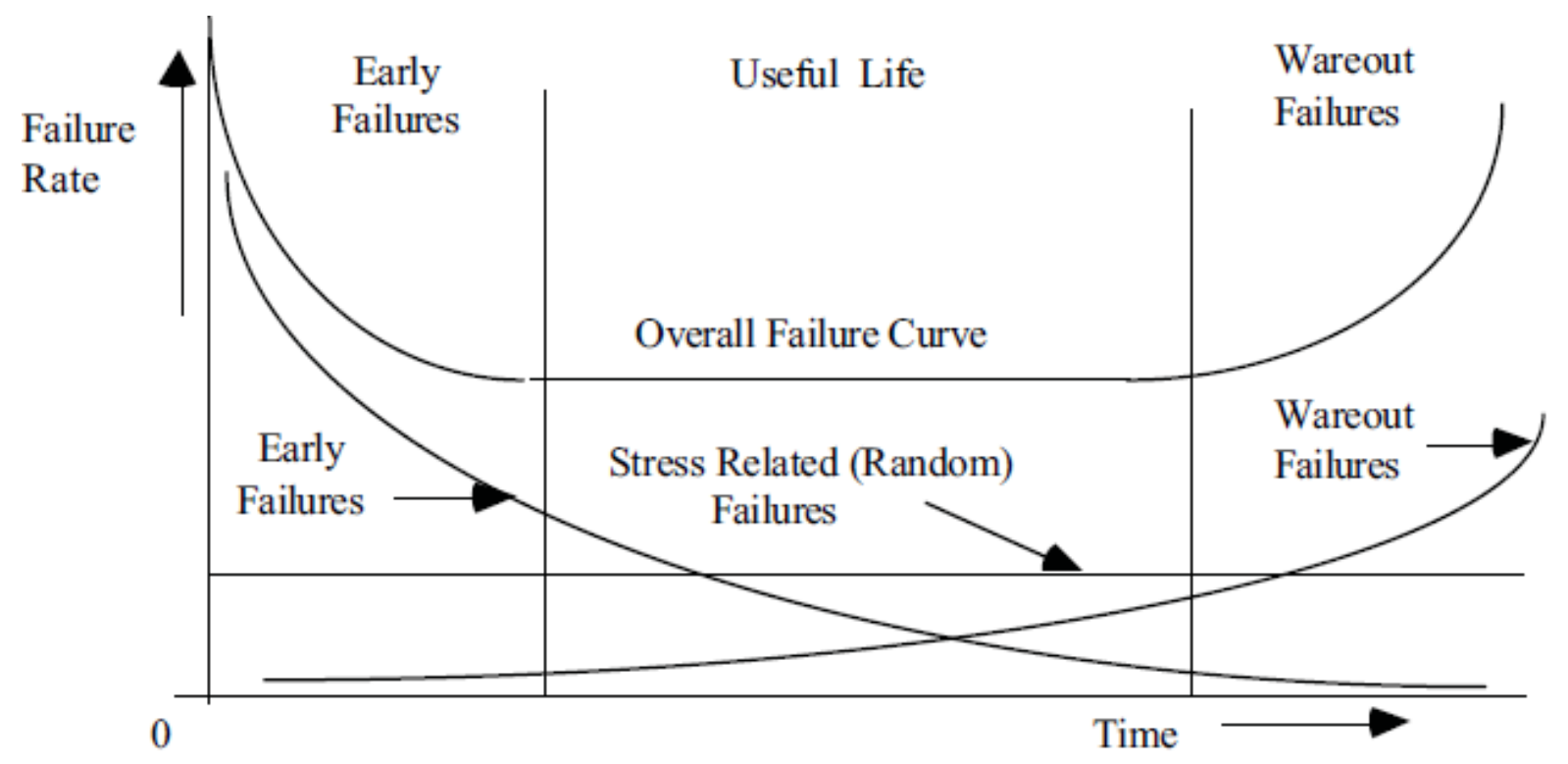

Fig. 17. Bath curve used to analyse the failure rate of wind energy components [62].

The first part of the curve shows the early failure rate of the components which are decreasing with time. The middle part shows the constant failure rate while the last part is ware out failure, increasing with time [63].

\section{Conclusion}

This paper investigated improvements in small scale wind energy system for a potential residential net-zero energy building. A 20 kVA PMSG is used at variable wind speed to manage and monitor the power flow at variable wind speed. The simulation results show the improved efficiency of the power flow parameters such as voltage, current, and power. MPPT based Perturb and observe method regulated the voltage closer to nominal values. The parallel UPS system could increase the system's reliability as it stores and supplies the power efficiently all the time. Buck-boost converter provided a constant voltage of $60 \mathrm{VDC}$ to charge the battery in the storage system irrespective of the variations in wind speed. This system is environmentally friendly and cost effective on a small-scale level. This type of design is easy to implement, cost effective, and simple. To store additional energy, future development should include adding solar modules and more UPS in a parallel arrangement.

\section{Acknowledgment}

Authors would like to thank the research facilities support provided by the Solar Thermal Vacuum Engineering Research Group at London Centre for Renewable Energy Engineering at London South Bank University. This research is self-funded and did not receive any specific grant from funding agencies in the public, commercial, or not-for-profit sectors. 


\begin{tabular}{|c|c|c|c|}
\hline Nomenclature & & Abbreviations & \\
\hline$T_{s}$ & Switching frequency $(\mathrm{Hz})$ & PWM & $\begin{array}{l}\text { Pulse width } \\
\text { modulation }\end{array}$ \\
\hline$V_{S}$ & $\begin{array}{l}\text { Storage system terminal voltage } \\
\text { (V) }\end{array}$ & PMSG & $\begin{array}{l}\text { Permanent magnet } \\
\text { synchronous generator }\end{array}$ \\
\hline$V_{p m s g}$ & Terminal voltage from PMSG & VDC & DC voltage \\
\hline$I_{S}$ & Storge current $(A)$ & MPPT & $\begin{array}{l}\text { Maximum power point } \\
\text { tracking algorithm }\end{array}$ \\
\hline$R_{g}$ & Stator resistance & UPS & $\begin{array}{l}\text { Uninterruptible power } \\
\text { supply }\end{array}$ \\
\hline$T_{m}$ & Mechanical torque & $\mathrm{P} \& \mathrm{O}$ & $\begin{array}{l}\text { Perturb and observe } \\
\text { technique }\end{array}$ \\
\hline$\omega_{e}$ & Rotational speed & kWh & Kilo watt hour \\
\hline$P_{t}$ & Wind turbine power & IGBT & $\begin{array}{l}\text { Insulated gate bipolar } \\
\text { transistor }\end{array}$ \\
\hline$\beta$ & Blade pitch angle & PDU & Power distribution unit \\
\hline$v$ & Wind speed & ATS & $\begin{array}{l}\text { Automatic transfer } \\
\text { switch }\end{array}$ \\
\hline$C_{p}$ & Power coefficient & $\mathrm{CU}$ & Control unit \\
\hline
\end{tabular}

\section{References}

[1] Pedersen, Jiesper Strandsbjerg Tristan, Filipe Duarte Santos, Detlef van Vuuren, Joyeeta Gupta, Ricardo Encarnação Coelho, Bruno A. Aparício, and Rob Swart. "An assessment of the performance of scenarios against historical global emissions for IPCC reports." Global Environmental Change 66 (2021): 102199.

https://doi.org/10.1016/i.gloenvcha.2020.102199

[2] Memon, S., T. Katsura, A. Radwan, S. Zhang, A. A. Serageldin, E. M. Abo-Zahhad, S. Sergey et al. "Modern eminence and concise critique of solar thermal energy and vacuum insulation technologies for sustainable lowcarbon infrastructure." International Journal of Solar Thermal Vacuum Engineering 1, no. 1 (2020): 52-71. ISSN online (2716-6953).

https://doi.org/10.37934/stve.1.1.5271

[3] Razmjoo, Armin, Meysam Majidi Nezhad, Lisa Gakenia Kaigutha, Mousa Marzband, Seyedali Mirjalili, Mehdi Pazhoohesh, Saim Memon, Mehdi A. Ehyaei, and Giuseppe Piras. "Investigating Smart City Development Based on Green Buildings, Electrical Vehicles and Feasible Indicators." Sustainability 13, no. 14 (2021): 7808. https://doi.org/10.3390/su13147808

[4] Memon, Saim. 2021. "The Scope of Advanced Smart Vacuum Insulation Technologies for Net-Zero Energy Buildings", Sustainable Energy Development and Innovation, WREC 2020. Springer Nature,

https://doi.org/10.1007/978-3-030-76221-6

[5] Memon, Saim, Olatunde Muisdeen Lawal, Sumair Ahmed Tariq, and Bilal Khalid. "Wave energy in the UK: Current scope, challenges and prognostications." International Journal of Solar Thermal Vacuum Engineering 2, no. 1 (2020): 59-78.

https://doi.org/10.37934/stve.2.1.4058

[6] Memon, Saim, Yueping Fang, Essam Mohamed Abo-Zahhad, O. Abdelrehim, Mohamed R. Elmarghany, Abdul Rashid Memon, Shanwen Zhang, and Amos Darko. "Factors influencing the performance parameters of vacuum glazed smart windows to net zero energy buildings." International Journal of Solar Thermal Vacuum Engineering 2, no. 1 (2020): 1-18.

https://doi.org/10.37934/stve.2.1.118

[7] Fang, Yueping, Saim Memon, Jingqing Peng, Mark Tyrer, and Tingzhen Ming. "Solar thermal performance of two innovative configurations of air-vacuum layered triple glazed windows." Renewable Energy 150 (2020): 167-175. 
https://doi.org/10.1016/j.renene.2019.12.115

[8] Zhang, Shanwen, Min Kong, Saim Memon, Hong Miao, Yanjun Zhang, and Sixing Liu. "Thermal Analysis of a New Neutron Shielding Vacuum Multiple Glass." Sustainability 12, no. 8 (2020): 3083.

https://doi.org/10.3390/su12083083

[9] Memon, Saim, Yueping Fang, and Philip C. Eames. "The influence of low-temperature surface induction on evacuation, pump-out hole sealing and thermal performance of composite edge-sealed vacuum insulated glazing." Renewable energy 135 (2019): 450-464.

https://doi.org/10.1016/i.renene.2018.12.025

[10] Miao, Hong, Lingcong Zhang, Sixing Liu, Shanwen Zhang, Saim Memon, and Bi Zhu. "Laser Sealing for Vacuum Plate Glass with PbO-TiO2-SiO2-RxOy Solder." Sustainability 12, no. 8 (2020): 3118. https://doi.org/10.3390/su12083118

[11] Memon, Saim, and Philip C. Eames. "Design and development of lead-free glass-metallic vacuum materials for the construction and thermal performance of smart fusion edge-sealed vacuum glazing." Energy and Buildings (2020): 110430. https://doi.org/10.1016/i.enbuild.2020.110430

[12] Ahmed, Mostafa, Ali Radwan, Ahmed Serageldin, Saim Memon, Takao Katsura, and Katsunori Nagano. "Thermal Analysis of a New Sliding Smart Window Integrated with Vacuum Insulation, Photovoltaic, and Phase Change Material." Sustainability 12, no. 19 (2020): 7846.

https://doi.org/10.3390/su12197846

[13] Memon, Saim. "Investigating energy saving performance interdependencies with retrofit triple vacuum glazing for use in UK dwelling with solid walls, Sustainable Development on Building and Environment." In Sustainable Development on Building and Environment: Proceedings of the 7th International Conference, 2015. ISBN-13: 978 0993120701.

[14] Memon, Saim. "Thermal Conductivity Measurement of Vacuum Tight Dual-Edge Seal for the Thermal Performance Analysis of Triple Vacuum Glazing." Impact of Thermal Conductivity on Energy Technologies (2018): 133.

http://dx.doi.org/10.5772/intechopen.74255

[15] Memon, Saim. "Design, development and thermal performance analysis of ultra-low heat loss triple vacuum glazing." In Solar World Congress 2017-Innovation for the 100\% renewable energy transformation. Abu Dhabi. (2017) ISBN 978-3-981 465 9-7-6.

https://doi.org/10.18086/swc.2017.15.04

[16] Memon, Saim, and Philip C. Eames. "Solar energy gain and space-heating energy supply analyses for solid-wall dwelling retrofitted with the experimentally achievable $U$-value of novel triple vacuum glazing." Journal of Daylighting 4, no. 1 (2017): 15-25.

https://doi.org/10.15627/jd.2017.2

[17] Memon, Saim, and Philip C. Eames. "Heat load and solar gain prediction for solid wall dwellings retrofitted with triple vacuum glazing for selected window to wall area ratios." In World Renewable Energy Forum, WREF 2012, vol. 6, pp. 4636-4643. ASES, 2012. ISBN: 9781622760923

[18] Memon, Saim. "Analysing the potential of retrofitting ultra-low heat loss triple vacuum glazed windows to an existing UK solid wall dwelling." International Journal of Renewable Energy Development (IJRED) 3, no. 3 (2014): 161-174.

https://doi.org/10.14710/ijred.3.3.161-174

[19] Memon, Saim. "Experimental measurement of hermetic edge seal's thermal conductivity for the thermal transmittance prediction of triple vacuum glazing." Case studies in thermal engineering 10 (2017): 169-178. https://doi.org/10.1016/i.csite.2017.06.002

[20] Memon, Saim, Farukh Farukh, Philip C. Eames, and Vadim V. Silberschmidt. "A new low-temperature hermetic composite edge seal for the fabrication of triple vacuum glazing." Vacuum 120 (2015): 73-82.

https://doi.org/10.1016/i.vacuum.2015.06.024

[21] Memon, Saim. "Design, fabrication and performance analysis of vacuum glazing units fabricated with low and high temperature hermetic glass edge sealing materials." PhD diss., Loughborough University, 2013.

https://dspace.lboro.ac.uk/2134/14562

[22] Memon, Saim, Farukh Farukh, and Karthikeyan Kandan. "Effect of cavity vacuum pressure diminution on thermal performance of triple vacuum glazing." Applied Sciences 8, no. 9 (2018): 1705.

https://doi.org/10.3390/app8091705 
[23] Memon, Saim, and Philip C. Eames. "Predicting the solar energy and space-heating energy performance for solidwall detached house retrofitted with the composite edge-sealed triple vacuum glazing." Energy Procedia 122 (2017): 565-570. https://doi.org/10.1016/i.egypro.2017.07.419

[24] Radwan, Ali, Takao Katsura, Saim Memon, Ahmed A. Serageldin, Makoto Nakamura, and Katsunori Nagano. "Thermal and electrical performances of semi-transparent photovoltaic glazing integrated with translucent vacuum insulation panel and vacuum glazing." Energy Conversion and Management 215 (2020): 112920. https://doi.org/10.1016/i.enconman.2020.112920

[25] Katsura, Takao, Saim Memon, Ali Radwan, Makoto Nakamura, and Katsunori Nagano. "Thermal performance analysis of a new structured-core translucent vacuum insulation panel in comparison to vacuum glazing: Experimental and theoretically validated analyses." Solar Energy 199 (2020): 326-346. https://doi.org/10.1016/i.solener.2020.02.030

[26] Zhang, Shanwen, Min Kong, Hong Miao, Saim Memon, Yanjun Zhang, and Sixing Liu. "Transient temperature and stress fields on bonding small glass pieces to solder glass by laser welding: Numerical modelling and experimental validation." Solar Energy 209 (2020): 350-362.

https://doi.org/10.1016/i.solener.2020.09.014

[27] Radwan, Ali, Takao Katsura, Saim Memon, Essam M. Abo-Zahhad, Ahmed A. Serageldin, and Katsunori Nagano. "Analysis of a vacuum-based photovoltaic thermal collector." Energy Reports 6 (2020): 236-242. https://doi.org/10.1016/j.egyr.2020.11.255

[28] Radwan, Ali, Takao Katsura, Saim Memon, Essam M. Abo-Zahhad, O. Abdelrehim, Ahmed A. Serageldin, Mohamed R. Elmarghany, Asmaa Khater, and Katsunori Nagano. "Development of a new vacuum-based photovoltaic/thermal collector, and its thermal and exergy analyses." Sustainable Energy \& Fuels 4, no. 12 (2020): 6251-6273.

https://doi.org/10.1039/DOSE01102A

[29] Memon, Saim, and Khawaja Noman Tahir. "Experimental and analytical simulation analyses on the electrical performance of thermoelectric generator modules for direct and concentrated quartz-halogen heat harvesting." Energies 11, no. 12 (2018): 3315.

https://doi.org/10.3390/en11123315

[30] Memon, Saim. "Advanced Thermoelectric Materials for Energy Harvesting Applications." .IntechOpen Publisher, London, ISBN: 978-1-78984-529-7, (2020).

https://doi.org/10.5772/intechopen.77430

[31] Memon, Saim, Maekele Mihreteab, Takao Katsura, Ali Radwan, Shanwen Zhang, Ahmed A. Serageldin, and Essam M. Abo-Zahhad. "Experimental and theoretical performance evaluation of parabolic trough mirror as solar thermal concentrator to thermoelectric generators." International Journal of Solar Thermal Vacuum Engineering 1, no. 1 (2020): 22-38. ISSN online (2716-6953). https://doi.org/10.37934/stve.1.1.2238

[32] Memon, Saim. "Introductory Chapter: Introduction to Advanced Thermoelectric Materials for Energy Harvesting Applications", Advanced Thermoelectric Materials for Energy Harvesting Applications, IntechOpen, London. (2019).

https://doi.org/10.5772/intechopen.89640

[33] Bensafi, Mohammed, Houari Ameur, Noureddine Kaid, Siamak Hoseinzadeh, Saim Memon, and Davide Astiaso Garcia. "Thermophysics Analysis of Office Buildings with a Temperature-Humidity Coupling Strategy Under HotArid Climatic Conditions." International Journal of Thermophysics 42, no. 8 (2021): 1-20.

https://doi.org/10.1007/s10765-021-02858-1

[34] Miller, Lee M., and David W. Keith. "Climatic impacts of wind power." Joule 2, no. 12 (2018): 2618-2632. https://doi.org/10.1016/i.joule.2018.09.009

[35] Naoi, Kazuhisa, and Mitsuhiro Shiono. "Relationship between Incident Angle of Wind on Rotor Blade and Output of a Drag-type Multi-blade Vertical-Axis Wind Turbine with Stationary Multi-vanes." In 2021 11th International Conference on Power, Energy and Electrical Engineering (CPEEE), pp. 147-152. IEEE, 2021. https://doi.org/10.1109/CPEEE51686.2021.938334

[36] Sohani, Ali, Mohammad Hassan Shahverdian, Hoseyn Sayyaadi, Siamak Hoseinzadeh, Saim Memon, Giuseppe Piras, and Davide Astiaso Garcia. "Energy and Exergy Analyses on Seasonal Comparative Evaluation of Water 
Flow Cooling for Improving the Performance of Monocrystalline PV Module in Hot-Arid Climate." Sustainability 13, no. 11 (2021): 6084.

https://doi.org/10.3390/su13116084

[37] Abo-Zahhad, Essam M., Shinichi Ookawara, Ali Radwan, Saim Memon, Yue Yang, M. F. El-Kady, and A. H. ElShazly. "Flow boiling in a four-compartment heat sink for high-heat flux cooling: A parametric study." Energy Conversion and Management 230 (2021): 113778.

https://doi.org/10.1016/j.enconman.2020.113778

[38] Khan, Asif, and Saim Memon. "Effect of hot-arid climatic solar energy on monocrystalline photovoltaic performance in Pakistan." International Journal of Solar Thermal Vacuum Engineering 2, no. 1 (2020): 19-39. https://doi.org/10.37934/stve.2.1.1939

[39] Memon, Saim, Gemeda Olani Nemera, and Tochukwu Israel Nwokeji. "Manifestations of carbon capture-storage and ambivalence of quantum-dot \& organic solar cells: An indispensable abridged review." International Journal of Solar Thermal Vacuum Engineering 2, no. 1 (2020): 40-58.

https://doi.org/10.37934/stve.2.1.4058

[40] Verde, A., O. Lastres, G. Hernández, G. Ibañez, L. Verea, and P. J. Sebastian. "A new method for characterization of small capacity wind turbines with permanent magnet synchronous generator: An experimental study." Heliyon 4, no. 8 (2018): e00732. https://doi.org/10.1016/j.heliyon.2018.e00732

[41] Syahputra, Ramadoni, and Indah Soesanti. "Performance improvement for small-scale wind turbine system based on maximum power point tracking control." Energies 12, no. $20 \quad$ (2019): 3938. https://doi.org/10.3390/en12203938

[42] weatherspark.com/y/45061/Average-Weather-in-City-of-London-United-Kingdom-Year-Round/Average wind speed.

[43] Errami, Y., Mohammed Ouassaid, and Mohamed Maaroufi. "Control of a PMSG based wind energy generation system for power maximization and grid fault conditions." Energy Procedia 42 (2013): 220-229.

https://doi.org/10.1016/i.egypro.2013.11.022

[44] Fantino, Roberto, Jorge Solsona, and Claudio Busada. "Nonlinear observer-based control for PMSG wind turbine." Energy 113 (2016): 248-257.

https://doi.org/10.1016/i.energy.2016.07.039

[45] Khan, Asif, Saim Memon, and Tariq Pervez Sattar. "Analyzing integrated renewable energy and smart-grid systems to improve voltage quality and harmonic distortion losses at electric-vehicle charging stations." IEEE Access 6 (2018): 26404-26415.

https://doi.ord/10.1109/ACCESS.2018.2830187

[46] Khan, Asif, Saim Memon, and T. P. Sattar. "Integration and management of solar energy for electric vehicle charging station." In Solar World Congress 2017-Innovation for the 100\% renewable energy transformation. Abu Dhabi, (2017). ISBN 978-3-981 465 9-7-6.

https://doi.org/10.18086/swc.2017.16.03

[47] Daoud, Ahmed A., Sobhy S. Dessouky, and Ahmed A. Salem. "Control scheme of PMSG based wind turbine for utility network connection." In 2011 10th International Conference on Environment and Electrical Engineering, pp. 1-5. IEEE, 2011.

https://doi.org/10.1109/EEEIC.2011.5874676

[48] Zhang, Yujia, Lei Zhang, and Yongwen Liu. "Implementation of maximum power point tracking based on variable speed forecasting for wind energy systems." Processes 7, no. 3 (2019): 158.

https://doi.org/10.3390/pr7030158

[49] Alayi, Reza, Farhad Zishan, Mahdi Mohkam, Siamak Hoseinzadeh, Saim Memon, and Davide Astiaso Garcia. "A Sustainable Energy Distribution Configuration for Microgrids Integrated to the National Grid Using Back-to-Back Converters in a Renewable Power System." Electronics 10, no. 15 (2021): 1826.

https://doi.org/10.3390/electronics10151826

[50] Makeen, Peter, Saim Memon, M. A. Elkasrawy, Sameh O. Abdullatif, and Hani A. Ghali. "Smart green charging scheme of centralized electric vehicle stations." International Journal of Green Energy (2021): 1-9.

https://doi.org/10.1080/15435075.2021.1947822

[51] Costanzo, Luigi, Alessandro Lo Schiavo, and Massimo Vitelli. "Design guidelines for the perturb and observe technique for electromagnetic vibration energy harvesters feeding bridge rectifiers." IEEE Transactions on Industry Applications 55, no. 5 (2019): 5089-5098. 


\section{https://doi.org/10.1109/TIA.2019.2923162}

[52] Makeen, Peter, Hani Ghali, and Saim Memon. "Controllable Electric Vehicle Fast Charging Approach Based on Multi-Stage Charging Current Methodology." In 2020 IEEE International Conference on Power and Energy (PECon), pp. 398-403. IEEE, 2020.

https://doi.org/10.1109/PECon48942.2020.9314471

[53] Makeen, Peter, Hani A. Ghali, and Saim Memon. "Experimental and Theoretical Analysis of the Fast Charging Polymer Lithium-Ion Battery Based on Cuckoo Optimization Algorithm (COA)." IEEE Access 8 (2020): 140486140496.

https://doi.org/10.1109/ACCESS.2020.3012913

[54] Zhu, Ying, Rui Zhao, and Jingtao Zhao. "Output power smoothing control for the PMSG based wind farm by using the allocation of the wind turbines." In 2017 20th International Conference on Electrical Machines and Systems (ICEMS), pp. 1-6. IEEE, 2017.

https://doi.org/10.1109/ICEMS.2017.8055952.

[55] Tang, Lixin, Limin Zhong, Muhammed Fazlur Rahman, and Yuwen Hu. "A novel direct torque control for interior permanent-magnet synchronous machine drive with low ripple in torque and flux-a speed-sensorless approach." IEEE Transactions on industry applications 39, no. 6 (2003): 1748-1756. https://doi.org/10.1109/TIA.2003.818981

[56] Lee, SoDuk, Jeff Cherry, Michael Safoutin, Joseph McDonald, and Michael Olechiw. "Modeling and validation of 48v mild hybrid lithium-ion battery pack." SAE International Journal of Alternative Powertrains 7, no. 3 (2018): 273-288.

https://www.jstor.org/stable/26789706

[57] Cen-wei, Shi, Qiu Jian-qi, Jin Meng-jia, and Friedrich W. Fuchs. "Study on the performance of different direct torque control methods for permanent magnet synchronous machines." (2005).

[58] Chen, Lei, Guocheng Li, Hongkun Chen, and Leong Hai Koh. "Combined Use of SFCL and SMES for Augmenting FRT Performance and Smoothing Output Power of PMSG Based Wind Turbine." In 2018 Asian Conference on Energy, Power and Transportation Electrification (ACEPT), pp. 1-5. IEEE. https://doi.org/10.1109/ACEPT.2018.8610758

[59] Putri, Ratna Ika, Margo Pujiantara, Ardyono Priyadi, Toshifumi Ise, and Mauridhi Hery Purnomo. "Maximum power extraction improvement using sensorless controller based on adaptive perturb and observe algorithm for PMSG wind turbine application." IET Electric Power Applications 12, no. 4 (2018): 455-462.

[60] Barros, L. S., and C. M. V. Barros. "An internal model control for enhanced grid-connection of direct-driven PMSG-based wind generators." Electric Power Systems Research 151 (2017): 440-450.

https://doi.org/10.1016/j.epsr.2017.06.014

[61] Yang, Bo, Tao Yu, Hongchun Shu, Xiaoshun Zhang, Kaiping Qu, and Lin Jiang. "Democratic joint operations algorithm for optimal power extraction of PMSG based wind energy conversion system." Energy Conversion and Management 159 (2018): 312-326. https://doi.org/10.1016/j.enconman.2017.12.090

[62] Ohring, Milton, and Lucian Kasprzak. Reliability and failure of electronic materials and devices. Academic Press, 2014.

[63] Mozayan, Seyed Mehdi, Maarouf Saad, Hani Vahedi, Handy Fortin-Blanchette, and Mohsen Soltani. "Sliding mode control of PMSG wind turbine based on enhanced exponential reaching law." IEEE Transactions on Industrial Electronics 63, no. 10 (2016): 6148-6159.

https://doi.org/10.1109/TIE.2016.2570718 